\section{Diversity and differences}

Henry R. Bourne

Transmembrane Signalling. Intracellular Messengers and Implications for Drug Development. Edited by Stefan R. Nahorski. Wiley: 1990. Pp. 248. £39, \$76.

G-Proteins as Mediators of Cellular Signalling Processes. Edited by M. D. Houslay and G. Milligan. Wiley: 1990. Pp. 232. £35, \$72.45.
TRANSMEMBRANE Signalling presents papers from a meeting held in the spring of 1989. As a symposium volume, it displays all the distinguishing marks of the genre. It is out of date. It promises more than it delivers. It neglects fundamental questions in favour of reciting facts collected in individual laboratories. More specifically, of fourteen chapters, nine are devoted to a single mode of transmembrane signalling, via $G$ proteins and their confederate receptors and effectors; the remaining five focus on a single network of intracellular messengers, the $\mathrm{Ca}^{2+} /$ phosphoinositide cascade. The book's title suggests that it might have accorded to receptor tyrosine kinases more than the offhand comment in chapter 8 , and to cyclic nucleotides more than the four pages on synthetic cyclic AMP analogues in chapter 14. Moreover, its pages provide not a single example of the "implications for drug

False advertising might be forgiven if the product were more timely or more interesting. Most chapters, however, contain little more than accounts of the research of one laboratory, about two years ago. Of the book's first 234 references (after which I stopped counting), only five cite papers published later than 1988. Sadly, detailed findings of a single laboratory - even a good one - do not become more fascinating as the years pass. In mid-1990, only a few chapters including those by Birnbaumer et al. (on $G$ proteins and ion channels), Irvine (inositol polyphosphates) and Pouyssegur et al. (G proteins and cell proliferation)are sufficiently thoughtful, provocative or comprehensive to merit attention. Note, however, that more recent reviews of the same subjects, in some cases by the same authors, are available at much lower cost, by taking the time to peruse a few current journals on library shelves.

Rather than embalming a venerable symposium, the editors of G-Proteins as Mediators of Cellular Signalling Processes have put together the first in a projected series of scholarly multi-author books on the "molecular pharmacology of cell regulation". In this case the book's title ought to be relevant to many biologists in an era when one can hardly open a journal without meeting GTP. Several chapters provide exactly what one seeks in a short monograph. Hall comprehensively surveys development" advertised in the subtitle. correctly describes its contents, which recent literature on Ras proteins and their relatives, making more than the usual amount of sense out of a plethora of diverse and sometimes contradictory experimental observations in many laboratories. Hingorani and Ho do the same for the well-studied $G$ protein of retinal photoreceptors, transducin; their bold representations of relations between transducin structure and function will provoke thought and experiment, even if some predictions turn out to be wrong.

In general, however, the book is not appreciably more up to date or comprehensive than the symposium volume. Again, references after 1988 are rare, and too many chapters concentrate on recounting experimental findings in their authors' own laboratories. Self-citations account for more than a quarter of the references in both books. The narrow focus characteristic of symposium contributions is especially inappropriate in scholarly summaries of a complex field.

$G$-Proteins would have profited from a more assertive editorial hand. The editors should have corrected obviously erroneous statements (for example, the attribution, on page 1 , of a single transmem- brane region to catalytic adenylyl cyclase), as well as the typographical errors found on almost every page (such as the "autonomic" functions of transducin, on page 101). They should have deconvoluted pompous, obscure prose in several chapters (see page 86 for a rich assortment of abominable sentences). They should have blue-pencilled the boring, repetitious accounts of $G$ proteins that introduce every chapter. Finally, far too many chapters portray a motley army of lonely facts - gel filtration profiles, immunoblots, amino-acid sequence motifs and graphs of something versus something else - wandering mindlessly across the page in search of an idea. The editors could have produced a much more interesting and readable book.

Every scientist can name at least one collection of scholarly reviews (even, perhaps, a symposium volume) that challenged active investigators, recruited new ones and enriched a field. But in many fast-moving research areas, the quality of most such tomes is negligible and likely to remain so. The root of the problem is not greedy publishers but scientists themselves. Some of us covet cheap air travel, paid for with a manuscript, while others just yearn to see our names in print. Who among us has not scribbled a rehash of past exploits without bothering about whether anyone will (or should) read it? We have met the enemy, and he is us.

Henry R. Boume is in the departments of Pharmacology and Medicine, University of California, San Francisco, California 94143, USA.

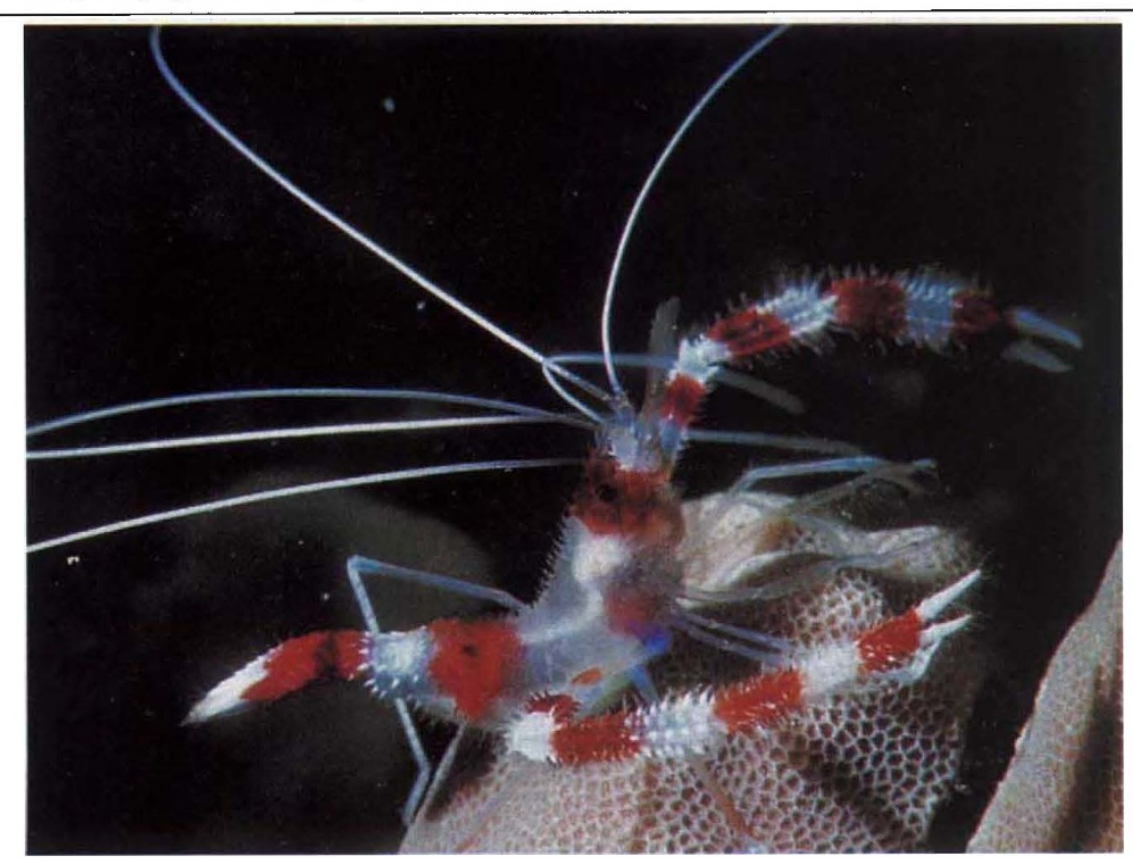

Stenopus hispidus, the banded coral shrimp, is the most distinctive of the shrimps common to the reefs of Hawaii. Taken from Hawaiian Reef Animals by E. Hobson and E.H. Clave, first published in 1972 and now reissued in a revised edition. The volume describes the vertebrate and invertebrate communities of the Hawaiian reef, and contains 85 colour plates of the variously decorated animals of the reef. Published by University of Hawaii Press, pbk \$19.95. 